\title{
USO DE FERTILIZANTE ORGANOFOSFATADO E TORTA DE FILTRO EM CANA-PLANTA
}

\author{
G. H. Vazquez ${ }^{1,2^{*}}$, R. Bortolin ${ }^{2}$, L. S. Vanzela ${ }^{2}$, C. dos S. B. Bonini ${ }^{3}$, A. Bonini Neto ${ }^{4}$ \\ ${ }^{1}$ Departamento de Fitotecnia, Tecnologia de Alimentos e Sócio Economia, UNESP - Univ \\ Estadual Paulista, Campus de Ilha Solteira, SP, Brasil \\ ${ }^{2}$ Departamento de Produção Vegetal, UNICASTELO, Fernandópolis, SP, Brasil \\ ${ }^{3}$ Departamento de solos, UNESP - Univ Estadual Paulista, Campus de Dracena, SP, Brasil \\ ${ }^{4}$ UNESP - Univ Estadual Paulista, Campus de Tupã, SP, Brasil
}

\section{RESUMO}

Objetivou-se neste trabalho comparar o efeito do uso de fertilizante organofosfatado e torta de filtro com fontes minerais na produtividade de biomassa, características agronômicas e tecnológicas da cana-planta e o retorno econômico obtido. O experimento foi instalado em Iturama/MG, em delineamento experimental em blocos casualizados com cinco repetições, sendo os tratamentos: $1=\mathrm{N}-\mathrm{P}-\mathrm{K}\left(27,135 \mathrm{e} 108 \mathrm{~kg} \mathrm{ha}^{-1}\right.$ respectivamente $)$, ou seja, $450 \mathrm{~kg} \mathrm{ha}^{-1}$ da fórmula 6-30-24; 2 = N-P-K $\left(60,120\right.$ e $\left.140 \mathrm{~kg} \mathrm{ha}^{-1}\right) ; 3=\mathrm{N}-\mathrm{P}-\mathrm{K}\left(14,84 \mathrm{e}^{2} 42 \mathrm{~kg} \mathrm{ha}^{-1}\right) ; 4=$ $700 \mathrm{~kg} \mathrm{ha}^{-1}$ de fertilizante organofosfatado (equivalente a 14,70 e $70 \mathrm{~kg} \mathrm{ha}^{-1} \mathrm{~N}-\mathrm{P}-\mathrm{K}$ ); $5=700$ $\mathrm{kg} \mathrm{ha}^{-1}$ de fertilizante organofosfatado $+10 \mathrm{t} \mathrm{ha}^{-1}$ de torta de filtro; $6=\mathrm{N}-\mathrm{P}-\mathrm{K}(27,135$ e 108 $\left.\mathrm{kg} \mathrm{ha}^{-1}\right)+10 \mathrm{tha}^{-1}$ de torta de filtro; $7=\mathrm{N}-\mathrm{P}-\mathrm{K}\left(60,135 \mathrm{e} 108 \mathrm{~kg} \mathrm{ha}^{-1}\right) ; 8=10 \mathrm{t} \mathrm{ha}^{-1}$ de torta de filtro $+108 \mathrm{~kg} \mathrm{ha}^{-1}$ de $\mathrm{K} ; 9=10 \mathrm{t} \mathrm{ha}^{-1}$ de torta de filtro $+\mathrm{N}+\mathrm{K}\left(27 \mathrm{e} 108 \mathrm{~kg} \mathrm{ha}^{-1}\right)$ e $10=$ $10 \mathrm{t} \mathrm{ha}^{-1}$ de torta de filtro + N-P-K $\left(30,50\right.$ e $\left.110 \mathrm{~kg} \mathrm{ha}^{-1}\right)$. Concluiu-se que as diversas doses e fontes de fósforo estudadas não interferiram na produtividade de biomassa da cana-planta; a torta de filtro proporcionou uma menor porcentagem de falhas de colmos na linha de cana-deaçúcar e o maior retorno econômico obtido foi com o uso conjunto da torta de filtro e o fertilizante organofosfatado em cana-planta.

Palavras-chave: resíduo; fósforo; adubação orgânica.

\section{USE OF ORGANOPHOSPHATED FERTILIZER AND FILTERCAKE IN PLANT- CANE}

\begin{abstract}
The aim of this work was to compare the effect of the use of organophosphated fertilizer and filtercake with mineral sources on biomass productivity, agronomic and technological characteristics of plant-cane and the economic return. The experiment was installed in Iturama/MG in a randomized blocks design with five repetitions, being the treatments: $1=\mathrm{N}-\mathrm{P}-\mathrm{K}\left(27,135\right.$ and $108 \mathrm{~kg} \mathrm{ha}^{-1}$ respectively), i.e. $450 \mathrm{~kg} \mathrm{ha}^{-1}$ of the formula 6-30-24; 2 = N-P-K $\left(60,120\right.$ and $\left.140 \mathrm{~kg} \mathrm{ha}^{-1}\right) ; 3=\mathrm{N}-\mathrm{P}-\mathrm{K}\left(14,84\right.$ and $\left.42 \mathrm{~kg} \mathrm{ha}^{-1}\right) ; 4=700 \mathrm{~kg}$ $\mathrm{ha}^{-1}$ organophosphated fertilizer $\left(14,70\right.$ and $\left.70 \mathrm{~kg} \mathrm{ha}^{-1} \mathrm{~N}-\mathrm{P}-\mathrm{K}\right) ; 5=700 \mathrm{~kg} \mathrm{ha}^{-1}$ organophosphated fertilizer $+10 \mathrm{tha}^{-1}$ filtercake; $6=\mathrm{N}-\mathrm{P}-\mathrm{K}\left(27,135\right.$ and $\left.108 \mathrm{~kg} \mathrm{ha}^{-1}\right)+10 \mathrm{t}$ ha $^{-1}$ filtercake; $7=\mathrm{N}-\mathrm{P}-\mathrm{K}\left(60,135\right.$ and $\left.108 \mathrm{~kg} \mathrm{ha}^{-1}\right) ; 8=10 \mathrm{t} \mathrm{ha}^{-1}$ filtercake $+108 \mathrm{~kg} \mathrm{ha}^{-1} \mathrm{~K} ; 9$ $=10 \mathrm{tha}^{-1}$ filtercake $+\mathrm{N}+\mathrm{K}\left(27\right.$ and $\left.108 \mathrm{~kg} \mathrm{ha}^{-1}\right)$ and $10=10 \mathrm{t} \mathrm{ha}^{-1}$ filtercake $+\mathrm{N}-\mathrm{P}-\mathrm{K}(30$, 50 and $110 \mathrm{~kg} \mathrm{ha}^{-1}$ ). It was concluded that the various levels and sources of phosphorus
\end{abstract}

"gisele@agr.feis.unesp.br 
studied did not affect the biomass productivity of the plant-cane; the filtercake provided a smaller percentage of failures of stalks in sugar cane line and the highest economic return was obtained by the joint use of filtercake and organophosphated fertilizer in plant-cane.

Keywords: residue; phosphorus; organic fertilization.

\section{INTRODUÇÃO}

O Brasil é o maior produtor mundial de cana-de-açúcar, o maior produtor e exportador de açúcar e o segundo maior produtor de etanol do mundo. O etanol produzido no Brasil obteve uma grande valorização nos últimos anos, por ser uma alternativa de energia renovável, limpa e menos poluente em relação à gasolina, por exemplo. Vários países já mostraram interesse em promover a mistura de etanol com a gasolina, o que não ocorre de forma corriqueira devido à proteção das indústrias com altas tarifas de importação, que distorcem o comércio, além de uso de barreiras não tarifárias (UNICA, 2008).

Já quanto à produtividade média de cana-de-açúcar no Brasil, em 1975 girava em torno de $45 \mathrm{t} \mathrm{ha}^{-1}$ e em 2014 atingiu $73,6 \mathrm{t} \mathrm{ha}^{-1}$ (CONAB, 2014). Se por um lado é indiscutível o ganho em produtividade da cultura nos últimos anos, quando comparado ao rendimento teórico máximo da cana-de-açúcar, que segundo Moore (2009) é superior a $472 \mathrm{t} \mathrm{ha}^{-1}$, o patamar alcançado chega a ser decepcionante.

O principal motivo dessa baixa produtividade é a expansão da cultura em solos de baixa fertilidade, que por sua vez, exigem manejo de adubação mais aprimorado para se obter produções economicamente viáveis.

A adubação, de maneira geral, pode ser definida pela necessidade nutricional da cultura subtraindo os nutrientes fornecidos pelo solo multiplicado por um fator de eficiência de absorção (f), ou seja, Adubação $=$ (planta - solo) $\mathrm{x}$ fator $(\mathrm{f})$ (VITTI, 2010).

Para a formação de $1,0 \mathrm{t}$ de colmos de cana-de-açúcar, estudos mostram valores que oscilam entre 0,90 a $1,32 \mathrm{~kg}$ de $\mathrm{N} ; 0,20$ a $0,69 \mathrm{~kg}$ de $\mathrm{P}_{2} \mathrm{O}_{5} ; 1,2$ a $1,8 \mathrm{~kg}$ de $\mathrm{K}_{2} \mathrm{O} ; 0,70$ a $0,95 \mathrm{~kg}$ de $\mathrm{CaO} ; 0,56$ a 0,86 $\mathrm{kg}$ de $\mathrm{MgO}$ e 0,30 a $0,36 \mathrm{~kg}$ de $\mathrm{S}$ (DEMATTÊ, 2004).

Já a quantidade de nutrientes extraída pelo conjunto colmo, folhas e palmito em 1,25 t de cana-de-açúcar é de: $1,2 \mathrm{~kg}$ de $\mathrm{N}$; $0,37 \mathrm{~kg}$ de $\mathrm{P}_{2} \mathrm{O}_{5} ; 1,49 \mathrm{~kg}$ de $\mathrm{K}_{2} \mathrm{O} ; 1,12 \mathrm{~kg}$ de $\mathrm{CaO} ; 0,68 \mathrm{~kg}$ de $\mathrm{MgO} ; 1,07 \mathrm{~kg}$ de $\mathrm{SO}_{4}$; $300 \mathrm{~g}$ de B, $270 \mathrm{~g}$ de $\mathrm{Cu} ; 8.900 \mathrm{~g}$ de Fe; $5.700 \mathrm{~g}$ de Mn e $720 \mathrm{~g}$ de $\mathrm{Zn}$ (MALAVOLTA et al., 1997).

A adubação da cana-de-açúcar varia da cana-planta para a cana-soca. No plantio, o açúcar presente no tolete favorece a associação entre bactérias fixadoras de $\mathrm{N}_{2}$ do ar e as raízes da cana, o que diminui a quantidade de nitrogênio a ser aplicada, havendo apenas a necessidade de elevadas quantidades de fósforo e potássio. Já na cana-soca é necessário adubar com altos teores de nitrogênio e potássio e baixo teor de fósforo, por não haver mais a presença do tolete, ou mesmo, devido à morte do sistema radicular que será substituído por outro originário da cana-soca (VITTI et al., 2006).

O fósforo apresenta alta taxa de fixação no solo, o que reduz o seu aproveitamento pelas plantas, tendo $\mathrm{o}$ ânion $\mathrm{H}_{2} \mathrm{PO}_{4}^{-}$forte afinidade pela superfície dos colóides dos óxidos de ferro e alumínio. As quantidades aplicadas, principalmente no plantio da cana, superam a quantidade extraída pela cultura (DEMATTÊ, 2004), sendo toda a dosagem de fósforo para os 5 anos da cultura aplicada no plantio (VITTI \& MAZZA, 2002).

Assim, a adubação visa completar a necessidade em nutrientes, mas quando se pensa nesta técnica, utilizando fertilizantes minerais e/ou orgânicos, a maior preocupação ocorre em relação às dosagens e os custos (DIAS \& ROSSETTO, 2006). 
A cana-de-açúcar é uma cultura que utiliza grandes quantidades de resíduos orgânicos produzidos pela própria agroindústria canavieira, como a vinhaça e a torta de filtro e que representam importantes aportes de matéria orgânica e de potássio e fósforo, respectivamente, colaborando para o uso racional desses materiais (ORLANDO FILHO, 1993).

A torta de filtro apresenta elevado porcentual de umidade (de 70 a $80 \%$ ) e teores elevados de matéria orgânica e fósforo, além de nitrogênio, cálcio e potássio (NUNES JÚNIOR, 2008), sendo empregada, principalmente, nas adubações da cana-planta e proporcionando ao agricultor uma economia nos custos de implantação da cultura.

A composição da torta de filtro é variável, em função do tipo de solo, variedade e maturação da cana, processo de clarificação do caldo e outros (ALMEIDA JUNIOR et al., 2011). O fósforo que predomina na torta é orgânico, o que juntamente com o nitrogênio por intermédio da mineralização e ataque de microrganismos do solo, apresentam lenta liberação, com alto aproveitamento pelas plantas (NUNES JÚNIOR, 2008).

A torta de filtro pode substituir a adubação normal de plantio, fazendo-se uma complementação com adubos minerais. Para se ter uma ideia de como seria tal complementação, é necessário se conhecer a composição de uma tonelada deste material, sendo, em média: $14,5 \mathrm{~kg}$ de Nitrogênio; $11,1 \mathrm{~kg}$ de $\mathrm{P}_{2} \mathrm{O}_{5} ; 7 \mathrm{~kg}$ de $\mathrm{K}_{2} \mathrm{O} ; 52,5 \mathrm{~kg}$ de $\mathrm{CaO}$ e $5,2 \mathrm{~kg}$ de $\mathrm{MgO}$ (KOFFLER \& DONZELLI, 1987). Assim,

\section{MATERIAL E MÉTODOS}

O experimento foi desenvolvido na Usina Coruripe, em Iturama/MG, no período de 12/04/2006 a 09/08/2007 (484 dias) em um solo classificado como Latossolo Vermelho Escuro (LVE-5), com as seguintes características químicas, na camada de $0-25 \mathrm{~cm}$ de profundidade: $\mathrm{pH}$ em $\mathrm{CaCl}_{2}=5,0 ; \mathrm{Al}^{3+}=2 \mathrm{mmol}_{\mathrm{c}} \mathrm{dm}^{-3} ; \mathrm{Ca}^{2+}$ $=16 \mathrm{mmol}_{\mathrm{c}} \mathrm{dm}^{-3} ; \mathrm{Mg}^{2+}=8 \mathrm{mmol}_{\mathrm{c}} \mathrm{dm}^{-3}$; $\mathrm{K}^{+}=0,4 \mathrm{mmol}_{\mathrm{c}} \mathrm{dm}^{-3} ; \mathrm{P}$ (resina) $=4 \mathrm{mg}$ para realizar a complementação, basta determinar a quantidade de torta economicamente aplicável por hectare, e depois por intermédio da análise de solo, faz-se a determinação das necessidades da cultura e subtrai-se o total de nutrientes fornecidos pela torta (FERNANDES, 1990).

Outra opção é o uso de fertilizantes organofosfatados, que utilizam um conjunto de matéria orgânica e microrganismos (fungos e bactérias) com capacidade de solubilizar fosfatos de rocha e disponibilizar fósforo para as culturas adubadas em substituição ao adubo fosfatado que utiliza ácido sulfúrico em sua fabricação (VILELA, 2005).

$\mathrm{O}$ uso de biofertilizantes organominerais na agricultura está em ascensão no mundo, pois proporciona efeitos benéficos para os solos e para o meio ambiente. Como as reservas de fosfatos conhecidas são finitas, qualquer estratégia que prolongue a vida útil destas irá contribuir para a sustentabilidade do planeta (QUEVEDO \& PAGANINI, 2011). De acordo com CORDELL (2008), no ritmo atual de exploração, as reservas de rocha fosfáticas conhecidas e exploráveis estarão extintas no período de 50 a 100 anos.

Diante do exposto, o presente trabalho teve como objetivo comparar o uso de fertilizante organofosfatado e torta de filtro com fontes minerais de nutrientes sobre a produtividade de biomassa, características agronômicas e tecnológicas da cana-planta e o retorno econômico obtido.

$\mathrm{dm}^{-3}$ e M.O. $=17 \mathrm{~g} \mathrm{dm}^{-3}$ e de $25-50 \mathrm{~cm}$ de profundidade: $\mathrm{pH} \mathrm{em} \mathrm{CaCl}_{2}=4,8 ; \mathrm{Al}^{3+}=2$ $\mathrm{mmol}_{\mathrm{c}} \mathrm{dm}^{-3} ; \mathrm{Ca}^{2+}=13 \mathrm{mmol}_{\mathrm{c}} \mathrm{dm}^{-3} ; \mathrm{Mg}^{2+}$ $=4 \mathrm{mmol}_{\mathrm{c}} \mathrm{dm}^{-3} ; \mathrm{K}^{+}=0,2 \mathrm{mmol}_{\mathrm{c}} \mathrm{dm}^{-3} ; \mathrm{P}$ $($ resina $)=5 \mathrm{mg} \mathrm{dm}^{-3}$ e M.O. $=12 \mathrm{~g} \mathrm{dm}^{-3}$.

$\mathrm{O}$ preparo de solo foi $\mathrm{o}$ convencional, com duas gradagens e uma subsolagem. Em seguida, foi semeada uma leguminosa (Crotalaria spectabilis L.) para realização de adubação verde. Sua 
incorporação foi realizada no florescimento, com o uso de uma grade niveladora.

Em 12/04/2006 foram abertos sulcos na área a 0,30 $\mathrm{m}$ de profundidade e sem adubo. Após a abertura dos sulcos, foram demarcadas as parcelas experimentais e distribuídas manualmente as diferentes dosagens de torta de filtro, adubação química e fertilizante organofosfatado de acordo com os tratamentos avaliados. A variedade plantada foi o cultivar CTC $3 \mathrm{em}$ uma densidade de 18 gemas $\mathrm{m}^{-1}$. Após o fechamento dos sulcos foi aplicado o cupinicida fipronil na dose de $250 \mathrm{~g} \mathrm{ha}^{-1}$ do produto comercial. Adicionalmente, o controle da Diatraea saccharalis foi feito com a liberação da vespa Cotesia flavipes

A cultura não foi irrigada, e os dados pluviométricos do período são apresentados na Tabela 1 .

Tabela 1. Dados pluviométricos mensais (mm) do experimento. Iturama/MG. 2006/2007.

\begin{tabular}{cccccccccccccc}
\hline Ano & Jan & Fev & Mar & Abr & Mai & Jun & Jul & Ago & Set & Out & Nov & Dez & Total \\
\hline 2006 & 278 & 280 & 174 & 25 & 28 & 0 & 0 & 56 & 66 & 21 & 70 & 110 & 1108 \\
2007 & 411 & 215 & 39 & 64 & 69 & 0 & 52 & 0 & 0 & 19 & 39 & 0 & 908 \\
\hline
\end{tabular}

Fonte: Usina Coruripe - Iturama/MG.

O detalhe da composição dos fertilizantes que compuseram os tratamentos aplicados é apresentado na Tabela 2.

Tabela 2. Detalhe das quantidades dos fertilizantes $\left(\mathrm{kg} \mathrm{ha}^{-1}\right)$ que compuseram os tratamentos.

\begin{tabular}{cccccc}
\hline $\begin{array}{c}\text { Tratament } \\
\mathbf{0 S}\end{array}$ & $\mathbf{N}$ & $\mathbf{P}_{\mathbf{2}} \mathbf{O}_{\mathbf{5}}$ & $\mathbf{K}_{\mathbf{2}} \mathbf{O}$ & Organofosfatado & Torta de filtro \\
\hline $1 *$ & 27 & 135 & 108 & - & - \\
$2 * *$ & 60 & 120 & 140 & - & - \\
$3 * *$ & 14 & 84 & 42 & - & - \\
4 & - & - & - & $700^{* * *}$ & - \\
5 & - & - & - & $700^{* * *}$ & 10000 \\
$6 * *$ & 27 & 135 & 108 & - & 10000 \\
$7 * *$ & 60 & 135 & 108 & - & - \\
$8 * *$ & - & - & 108 & - & 10000 \\
$9 * *$ & 27 & - & 108 & - & 10000 \\
$10 * *$ & 30 & 50 & 110 & - & 10000 \\
\hline
\end{tabular}

* fórmula 6-30-24 (450 $\left.\mathrm{kg} \mathrm{ha}^{-1}\right)$ adubação comumente empregada na usina local.

**fonte de $\mathrm{N}-\mathrm{P}_{2} \mathrm{O}_{5}-\mathrm{K}_{2} \mathrm{O}$ utilizada: ureia, super fosfato triplo e cloreto de potássio, respectivamente.

*** equivalente a 14,70 e $70 \mathrm{~kg} \mathrm{ha}^{-1} \mathrm{de} \mathrm{N}-\mathrm{P}_{2} \mathrm{O}_{5}-\mathrm{K}_{2} \mathrm{O}$, respectivamente.

A formulação do fertilizante organofosfatado utilizado foi a 2-10-10 acrescida de $5 \%$ de $\mathrm{S}, 12 \%$ de $\mathrm{Zn}, 1,6 \%$ de B, $1,6 \%$ de $\mathrm{Cu}$ e $8 \%$ de $\mathrm{Mn}$ e a da torta de filtro empregada está apresentada na Tabela 3.

O delineamento experimental adotado foi o de blocos casualizados com
10 tratamentos e 5 repetições. As parcelas foram constituídas de 6 linhas de $14 \mathrm{~m}$ de comprimento e com espaçamento entre linhas de $1,5 \mathrm{~m}$, num total de $126 \mathrm{~m}^{2}$ por parcela, sendo avaliadas apenas as quatro linhas centrais, desprezando uma linha de cada lado como bordadura (parcela útil). 
Tabela 3. Composição da torta de filtro empregada no experimento.

\begin{tabular}{ccc}
\hline Variável & Umidade natural & Base seca (110 $\mathbf{C})$ \\
\hline $\mathrm{pH}$ em $\mathrm{CaCl}_{2}$ 0,01M & 5,9 & - \\
Umidade total & $70,42 \%$ & 0,00 \\
Carbono orgânico & $10,39 \%$ & $35,13 \%$ \\
Nitrogênio total & $0,53 \%$ & $1,79 \%$ \\
Fósforo $\left(\mathrm{P}_{2} \mathrm{O}_{5}\right)$ total & $0,75 \%$ & $2,54 \%$ \\
Potássio $\left(\mathrm{K}_{2} \mathrm{O}\right)$ total & $0,03 \%$ & $0,10 \%$ \\
Cálcio $(\mathrm{Ca})$ total & $0,92 \%$ & $3,11 \%$ \\
Magnésio $(\mathrm{Mg})$ total & $0,11 \%$ & $0,37 \%$ \\
Enxofre $(\mathrm{S})$ total & $0,01 \%$ & $0,03 \%$ \\
\hline
\end{tabular}

Fonte: Análise realizada pelo Laboratório da Usina Coruripe, Iturama/MG, 2007.

As variáveis agronômicas analisadas foram:

- Colmos por metro: foi contado o número de perfilhos de todas as linhas da parcela útil aos 281 DAP (dias após o plantio).

- Porcentagem de falhas: foi contado o número de espaços vazios na linha de plantio (contabilizado quando maiores que $0,5 \mathrm{~m})$ com o auxílio de um gabarito de $0,5 \mathrm{~m}$ em toda a parcela útil aos 281 DAP.

- Produtividade de biomassa: aos 484 DAP, após a queima, todos os colmos de cada parcela útil foram cortados e pesados usando-se uma célula de carga acoplada na garra de uma pá carregadeira e em seguida, calculou-se a produção em toneladas de cana de biomassa por hectare.

- Índice de infestação de brocas (II\%): após a colheita, foram retirados ao acaso 10 colmos por parcela útil e procedeu-se ao cálculo utilizando-se a seguinte fórmula:

$$
I I \%=\frac{N E P}{N T E} \times 100
$$

em que,

II - índice de infestação

NEP - número de entrenós perfurados;

NTE - número total de entrenós.

- Análise tecnológica: foram coletados dez colmos de cada parcela útil para a determinação do Pol (porcentagem de sacarose - PCC) e do Açúcar total recuperável (ATR).
Quanto à análise econômica, os preços utilizados para o cálculo do custo dos adubos (CA) foram levantados em estabelecimentos comerciais da região de Fernandópolis/SP (distante $70 \mathrm{~km}$ de Iturama/MG) em setembro/2014. A torta de filtro não foi contabilizada, já que ela é um subproduto da agroindústria canavieira. A receita bruta (RB) foi determinada multiplicando-se a produtividade de biomassa de cada tratamento pela sua quantidade de ATR por tonelada e finalmente pelo preço da ATR. O preço médio da ATR em $\mathrm{R} \$ \mathrm{~kg}^{-1}$ de acordo com o Consecana no Estado de São Paulo utilizado foi o do mês de setembro/2014 e alcançava o valor de $\mathrm{R} \$ 0,4554$ (UDOP, 2014). Por sua vez, foi considerada a estimativa do custo de produção $(\mathrm{CP})$ da cana-de-açúcar em São Paulo na safra 2014 de $\mathrm{R} \$ 5.776,00$ por hectare no primeiro corte (AGRIANUAL, 2014). Assim, o retorno econômico (RE) obtido em cada tratamento foi calculado pela diferença entre a $\mathrm{RB}$ e o $(\mathrm{CP}+\mathrm{CA})$.

Para a análise estatística das variáveis agronômicas foi utilizado o software ESTAT. Os dados em porcentagem de falhas e de infestação de brocas foram transformados em arc sen $\sqrt{x / 100}$. Os resultados, quando significativos pelo teste $\mathrm{F}$, foram analisados pelo teste de Tukey a $5 \%$ de probabilidade. 


\section{RESULTADOS E DISCUSSÃO}

Os resultados médios referentes a número de colmos por metro, porcentagem de falhas e produtividade de biomassa na cultura da cana-de-açúcar nos diversos tratamentos aplicados são apresentados na Tabela 4.

Tabela 4. Resultados médios referentes a número de colmos por metro, porcentagem de falhas e produtividade de biomassa. Iturama/MG, 2007.

\begin{tabular}{cccc}
\hline Tratamentos & $\mathbf{N}^{\mathbf{0}}$ colmos $\mathbf{~ m}^{-1}$ & $\begin{array}{c}\text { Falhas } \\
(\boldsymbol{\%})\end{array}$ & $\begin{array}{c}\text { Produtividade de } \\
\text { biomassa }\left(\mathbf{t ~ h a}^{\mathbf{- 1}}\right)\end{array}$ \\
\hline 1 & 11,0 & $* 6,8(1,5) \mathrm{ABC}$ & 114,2 \\
2 & 10,9 & $9,3(2,7) \mathrm{AB}$ & 116,0 \\
3 & 10,8 & $9,8(3,1) \mathrm{A}$ & 110,7 \\
4 & 11,2 & $9,2(2,7) \mathrm{AB}$ & 121,5 \\
5 & 11,5 & $4,2(0,9) \mathrm{ABC}$ & 124,3 \\
6 & 11,4 & $2,3(0,4) \mathrm{C}$ & 125,2 \\
7 & 11,1 & $7,6(2,2) \mathrm{ABC}$ & 113,8 \\
8 & 11,8 & $6,3(1,3) \mathrm{ABC}$ & 116,4 \\
9 & 11,6 & $2,7(0,6) \mathrm{BC}$ & 118,0 \\
10 & 11,2 & $5,9(1,4) \mathrm{ABC}$ & 117,5 \\
\hline $\mathrm{DMS}$ & 1,12 & 6,72 & 15,00 \\
\hline $\mathrm{CV}(\%)$ & 4,70 & 49,19 & 5,98 \\
\hline
\end{tabular}

Médias seguidas pela mesma letra na coluna não diferem entre si, pelo teste de Tukey, ao nível de $5 \%$ de probabilidade.

*Médias transformadas em arc sen $\sqrt{x+100}$ e médias originais entre parênteses.

Não houve diferença significativa na avaliação do número de colmos por metro a 5\% de significância pelo Teste F, como mostrado na Tabela 4. Assim, constatou-se que não ocorreu interferência da fonte e da quantidade de fósforo empregada sobre o perfilhamento da cana-de-açúcar.

Dados da literatura relatam aumento no volume de raízes em decorrência de acréscimos no teor de fósforo no solo (VITTI et al., 2006), o que por sua vez garante um maior número de colmos por hectare e produtividade de biomassa. Porém, nesse experimento mesmo com doses de fósforo variando de $70 \mathrm{~kg} \mathrm{ha}^{-1} \mathrm{a}$ $210 \mathrm{~kg} \mathrm{ha}^{-1}(75 \mathrm{~kg}$ provenientes da torta e $135 \mathrm{~kg}$ solúvel) este acréscimo não ocorreu. Da mesma forma, não houve interferência do uso da torta de filtro, mesmo sabendo-se que essa possui $70,4 \%$ de água (Tabela 3), o que poderia favorecer o desenvolvimento inicial das plantas em uma época tradicionalmente mais seca. Neste caso, provavelmente a disponibilidade de água foi suficiente durante os primeiros estágios da cultura, pois segundo Matioli (1998) a aplicação de uma lâmina de $30 \mathrm{~mm}$ em uma cana-soca já é suficiente para garantir aumentos na produtividade.

Também não houve interferência do uso do fertilizante organofosfatado sobre o número de colmos. Santos et al. (2009) em um experimento em Coruripe/AL com 10 tratamentos: 1. Testemunha; 2. NK + micro; 3. Superfosfato simples; 4. Superfosfato triplo; 5. Fosmag; 6. Gafsa; 7. MAP; 8. Fórmula 06-26-24 (460 kg ha ${ }^{-1}$ ); 9. Composto (mistura de torta de filtro, bagaço e cinzas); e 10. Superfosfato simples parcelado, também relataram não haver efeito significativo do uso de diferentes fontes de fosforo sobre a população de perfilhos da cana-planta.

O perfilhamento inicial é afetado por muitos fatores, tais como: luz, temperatura, umidade do solo e nutrientes, que são manejados por meio de espaçamento, profundidade, época de plantio, época de corte, controle de pragas e doenças. Já a 
sobrevivência dos perfilhos até a maturidade é de certa forma uma medida de caráter varietal, mas é influenciada pelo clima, solo e condições ambientais (BEAUCLAIR \& SCARPARI, 2006).

O experimento foi instalado no dia 12/04/2006, mês que acumulou precipitação total de $25 \mathrm{~mm}$ e no mês seguinte, $28 \mathrm{~mm}$ (Tabela 1), quantidades que garantiram a brotação e um bom desenvolvimento inicial dos colmos. Nos meses seguintes, até a data da determinação do número de colmos por metro (cana com 281 dias em 18/01/2007), as precipitações totalizaram $734 \mathrm{~mm}$, proporcionando um bom crescimento das plantas. A precipitação durante todo o ciclo da cultura foi de $1.226 \mathrm{~mm}$, o que atendeu às necessidades da planta, já que a canade-açúcar necessita de 1.200 a $1.300 \mathrm{~mm}$ de água distribuída uniformemente (MARIN, 2008).

A média geral do número de colmos por metro na colheita foi de 11,2, o que totalizou 74.667 colmos por hectare, estando próximo da capacidade média de perfilhamento descrita por Landell et al. (2002) em cana-de-açúcar variedade IAC 86-2480, que é de 12-13 perfilhos por metro.

A variável porcentual de falhas foi influenciada significativamente pelos tratamentos (Tabela 4). O tratamento 6 $(\mathrm{NPK}+$ Torta) apresentou a menor porcentagem de falhas $(0,4 \%)$, superando estatisticamente os tratamentos 3 (NPK 1470-70), 2 (NPK 60-120-140) e 4 (Fertilizante organofosfatado), mas não diferiu dos demais. Neste caso, a umidade presente na torta de filtro proporcionou uma menor ocorrência de falhas na área quando comparada aos adubos minerais.

Sabe-se que a matéria orgânica presente na torta de filtro por ser higroscópica, sendo capaz de reter água em até seis vezes pessoa sua própria massa, aumenta a capacidade de retenção de água do solo, contribuindo para assegurar melhor brotação em plantios realizados em épocas desfavoráveis, principalmente em regime não irrigado (ALLEONI \&
BEAUCLAIR， 1995; ROSSETTO \& DIAS, 2005).

Quanto à produtividade de biomassa (Tabela 4), não houve diferenças estatísticas com o uso das diferentes doses de nutrientes minerais ou mesmo das fontes, torta de filtro e fertilizante organofosfatado. Sabe-se que tanto a torta de filtro, quanto o fertilizante organofosfatado, possuem elementos minerais que não estão prontamente disponíveis às plantas, portanto, a resposta nutricional desses elementos pode não ter aparecido no primeiro corte da cana-deaçúcar.

Penatti \& Boni (1989) trabalhando em um Latossolo Vermelho Amarelo com a variedade SP70-1143 variaram as doses de torta de filtro fresca em 5, 10, $15 \mathrm{t} \mathrm{ha}^{-1}$, todas juntamente com a adubação mineral, e concluíram que a partir do $3^{\circ}$ corte $o$ canavial passou a apresentar diferenças significativas em produtividade favoráveis as doses crescentes de torta de filtro, mostrando efeito residual da torta, além de observar um aumento no teor de cálcio no solo em relação à área não tratada com torta.

Já Garcia (2005) testando fonte orgânica de adubo isoladamente e associada a doses de fósforo solúvel, mostrou que as fontes orgânicas de fósforo aplicadas isoladamente proporcionam média semelhante de produtividade às associadas ao adubo mineral, ou ainda, quando da aplicação do adubo mineral isoladamente.

No entanto, o objetivo deste trabalho não foi substituir totalmente a adubação fosfatada e sim parte da necessidade por meio do uso de fontes mais econômicas e ambientalmente corretas, como a torta de filtro e os fertilizantes organofosfatados, principalmente neste momento de alta no preço dos fertilizantes. Além disso, sabe-se que ao longo do tempo as fontes de fósforo solúvel perdem eficiência, pois ocorre a fixação deste elemento pelo solo (KORNDÖRFER et al. 1989). Para aumentar a eficiência da adubação fosfatada em lavouras de cana-de-açúcar, Bittencourt et al. (2006) recomendam 
utilizar um carregador orgânico, como a torta de filtro, para aumentar a massa e proteger o fósforo da fixação.

A porcentagem de infestação de broca não apresentou diferenças significativas de acordo com os diversos tratamentos estudados (Tabela 5), o que concorda com Garcia et al. (2012) que estudando a interferência de fontes de adubação (sem adubação, torta de filtro + vinhaça; torta de filtro+vinhaça+50\% da adubação fosfatada; torta de filtro+vinhaça + $100 \%$ da adubação fosfatada e adubação mineral) sobre a intensidade de infestação de broca (Diatraea saccharalis) na cultura da cana de açúcar, concluíram que não houve diferenças. De modo geral, segundo a classificação de Gallo et al. (2002), a porcentagem de infestação de broca foi elevada (média de 19\%), devido provavelmente, as condições ambientais ou mesmo, características da variedade.

Tabela 5. Resultados médios referentes a porcentagem de infestação de brocas, pol porcento cana (PCC) e açúcar total recuperável (ATR). Iturama/MG, 2007.

\begin{tabular}{cccc}
\hline Tratamentos & \% Infestação de broca & PCC $(\%)$ & ATR \\
\hline 1 & $* 25,7(19,1)$ & $15,57 \mathrm{~A}$ & $152,69 \mathrm{~A}$ \\
2 & $27,8(21,8)$ & $15,44 \mathrm{AB}$ & $151,50 \mathrm{AB}$ \\
3 & $25,4(18,5)$ & $15,29 \mathrm{ABC}$ & $150,19 \mathrm{ABC}$ \\
4 & $26,5(19,9)$ & $14,67 \mathrm{ABC}$ & $144,52 \mathrm{ABC}$ \\
5 & $26,9(20,3)$ & $15,14 \mathrm{ABC}$ & $149,08 \mathrm{ABC}$ \\
6 & $27,2(21,0)$ & $14,30 \mathrm{BC}$ & $141,01 \mathrm{BC}$ \\
7 & $24,6(17,5)$ & $14,74 \mathrm{ABC}$ & $145,15 \mathrm{ABC}$ \\
8 & $25,2(18,2)$ & $15,24 \mathrm{ABC}$ & $149,71 \mathrm{ABC}$ \\
9 & $24,2(17,0)$ & $14,14 \mathrm{C}$ & $139,69 \mathrm{C}$ \\
10 & $23,6(16,3)$ & $14,85 \mathrm{ABC}$ & $146,27 \mathrm{ABC}$ \\
\hline DMS & 5,50 & 1,21 & 10,88 \\
\hline CV $(\%)$ & 10,04 & 3,80 & 3,47 \\
\hline
\end{tabular}

Médias seguidas pela mesma letra na coluna não diferem entre si, pelo teste de Tukey, ao nível de 5\% de probabilidade.

*Médias transformadas em arc sen $\sqrt{x+100}$ e médias originais entre parênteses.

A pol (PCC) do tratamento 1 (NPK 27-135-108) superou estatisticamente as dos tratamentos 6 (NPK 27-135-108 + Torta) e 9 (Torta + NK), mas não diferiu dos demais (Tabela 5). De maneira geral, não houve interferência de fontes e doses de fósforo utilizadas no plantio de cana-deaçúcar, o que concorda com Cruz et al. (2009) e Caione et al. (2011) que verificaram que o teor de ${ }^{\circ}$ Brix não foi influenciado pela dose e pela fonte de fósforo, respectivamente.

A média geral da PCC do experimento foi de $14,94 \%$, e poderia ter alcançado um valor maior (16-17\%), caso a cultura tivesse sido colhida mais tardiamente, já que a variedade CTC 3 é recomendada para o final de safra. O ATR apresentou a mesma tendência da Pol (Tabela 5), atingindo valores médios de 146,98 .

$\mathrm{Na}$ Tabela 6 estão apresentadas as receitas brutas $(\mathrm{RB})$ de cada tratamento, os custos de produção (CP) e dos adubos (CA) e o retorno econômico obtido [RE = $\mathrm{RB}-(\mathrm{CP}+\mathrm{CA})]$. Optou-se por apresentar o custo dos adubos (CA) de forma isolada ao do custo de produção (CP) com o objetivo de facilitar a visualização das diferenças monetárias entre os tratamentos. 
Tabela 6. Receita bruta, custo de produção e dos adubos e retorno econômico obtido nos diversos tratamentos estudados.

\begin{tabular}{|c|c|c|c|c|}
\hline Tratamentos & $\begin{array}{c}\text { Receita Bruta } \\
(\mathrm{RB}) \\
\left(\mathrm{R} \$ \mathrm{ha}^{-1}\right)\end{array}$ & $\begin{array}{c}\text { Custo de } \\
\text { Produção }(\mathrm{CP}) \\
\left(\mathrm{R} \$ \mathrm{ha}^{-1}\right)\end{array}$ & $\begin{array}{c}\text { Custo dos } \\
\text { Adubos (CA) } \\
\left(\mathrm{R} \$ \mathrm{ha}^{-1}\right)\end{array}$ & $\begin{array}{c}\text { Retorno } \\
\text { Econômico }(\mathrm{RE}) \\
\left(\mathrm{R} \$ \mathrm{ha}^{-1}\right)\end{array}$ \\
\hline $5 * * *$ & $8.438,86$ & $5.776,00$ & 645,40 & $2.017,46$ \\
\hline $8 * *$ & $7.935,91$ & $5.776,00$ & 260,69 & $1.899,22$ \\
\hline $4 *$ & $7.996,45$ & $5.776,00$ & 645,40 & $1.575,05$ \\
\hline $10 * *$ & $7.826,83$ & $5.776,00$ & 554,16 & $1.496,67$ \\
\hline 1 & $7.940,90$ & $5.776,00$ & 738,00 & $1.426,90$ \\
\hline $9 * *$ & $7.506,55$ & $5.776,00$ & 340,46 & $1.390,09$ \\
\hline $6 * *$ & $8.039,84$ & $5.776,00$ & 880,46 & $1.383,38$ \\
\hline 3 & $7.571,50$ & $5.776,00$ & 478,74 & $1.316,76$ \\
\hline 2 & $8.003,20$ & $5.776,00$ & 995,20 & $1.232,00$ \\
\hline 7 & $7.522,33$ & $5.776,00$ & 977,96 & 768,37 \\
\hline
\end{tabular}

*com fertilizante organofosfatado

$* *$ com torta de filtro

*** com fertilizante organofosfatado e torta de filtro

Os três maiores retornos econômicos foram obtidos nos tratamentos que utilizaram o fertilizante organofosfatado e a torta de filtro (T5), torta de filtro + potássio (T8) e fertilizante organofosfatado (T4). A adubação normalmente empregada pela usina (T1) mostrou uma receita $\mathrm{R} \$$ 590,56 inferior ao melhor tratamento (T5).

$\mathrm{O}$ retorno econômico obtido com o uso do fertilizante organofosfatado acrescido de torta de filtro (T5) superou todos os tratamentos que empregaram adubos minerais e mostrou ser uma boa opção de redução de custos. Segundo Alvarenga \& Queiroz (2008) dados

\section{CONCLUSÃO}

As diversas fontes e doses de fósforo estudadas não interferem na produtividade de biomassa da cana-planta.

A torta de filtro proporciona uma menor porcentagem de falhas de colmos na linha de cana-de-açúcar.

\section{REFERÊNCIAS}

AGRIANUAL. Anuário estatístico da agricultura brasileira. São Paulo: Instituto FNP, 2014. 472p. divulgados pela UDOP (União dos Produtores de Bioenergia) mostram que é possível reduzir em cerca de US\$ 60 por hectare os custos de produção da cana-deaçúcar por meio da substituição dos adubos químicos pela torta de filtro e a vinhaça.

Esses dados são de uma primeira safra, devendo haver resultados promissores com o uso tanto de torta, quanto de fertilizante organofosfatado nos demais anos, visto que esses materiais possuem elementos que são solubilizados após certo tempo.

O maior retorno econômico foi obtido com o uso do conjunto da torta de filtro e o fertilizante organofosfatado em cana-planta.

A torta de filtro e o fertilizante organofosfatado são alternativas viáveis no cultivo de cana-de-açúcar.

ALLEONI, L. R. F.; BEAUCLAIR, E. G. F. Cana-de-açúcar cultivada após milho e amendoim, com diferentes doses de adubo. Scientia Agricola, Piracicaba, v.52, n.3, p.409-415, 1995. 
ALMEIDA JÚNIOR, A. B.; NASCIMENTO, C. W. A.; SOBRAL, M. F. et al. Fertilidade do solo e absorção de nutrientes em cana-de-açúcar fertilizada com torta de filtro. Revista Brasileira de Engenharia Agrícola e Ambiental, Campina Grande, v.15, n.10, p.1004-1013, 2011. <http://dx.doi.org/10. 1590/S141543662011001000004>

ALVARENGA, R. P.; QUEIROZ, T. R. Caracterização dos aspectos e impactos econômicos, sociais e ambientais do setor sucroalcooleiro Paulista. In: CONGRESSO DA SOCIEDADE BRASILEIRA DE ECONOMIA, ADMINISTRAÇÃO E SOCIOLOGIA RURAL, 46., 2008, Rio Branco. Anais... Rio Branco, 2008. p.21.

BEAUCLAIR, E. G. F.; SCARPARI, M. S. Noções fitotécnicas. In: RIPOLI, T. C. C.; RIPOLI, M. L. C.; CASAGRANDI, D. V. et al. Plantio de cana-de-açúcar: Estado da Arte. Piracicaba: T. C. C. Ripoli, 2006. p.80-91.

BITTENCOURT, V. C.; STRINI, A. C.; CESARIM, L. G. et al. Torta de filtro enriquecida. Idea News, Ribeirão Preto, v.6, n.63, p.2-6, 2006.

CAIONE, G.; LANGE, A.; BENETT, C. $\mathrm{G}$. S. et al. Fontes de fósforo em variedades de cana-de-açúcar forrageira. Pesquisa Agropecuária Tropical, Goiânia, v.41, n.1, p.66-73, 2011.

CONAB. Companhia Nacional de Abastecimento. Acompanhamento da safra brasileira de cana-de-açúcar, safra 2014/15. Brasília, v.1, p.1-20, 2014. <http://www.conab.gov.br/OlalaCMS/uplo ads/arquivos/14_04_15_15_44_37_boletim _cana_portugues_-_1o_lev_-_14.pdf $>.10$ ago. 2014.

CORDELL, D. The story of phosphorus: missing global governance of a critical resource. 2008. $<$ http://phosphorusfutures.net/files/DCorde 11_SENSEpaper.pdf>. 10 ago. 2014.
CRUZ, S. J. S.; OLIVEIRA, S. S. C; CRUZ, S. C. S. et al. Efeito da adubação fosfatada sobre o acúmulo de biomassa e teor de Brix de duas variedades de canade-açúcar. Revista Caatinga, Mossoró, v.22, n.2, p.110-116, 2009.

DEMATTÊ, J. L. I. Recuperação e manutenção da fertilidade dos solos. Visão Agrícola, Piracicaba, v.1, n.1, p.48-59, 2004.

DIAS, F. L. F.; ROSSETTO, R. Calagem e adubação da cana-de-açúcar. In: SEGATO, S. V.; PINTO, A. de S.; JENDIROBA, E. et al. Atualização em produção de canade-açúcar. Piracicaba: CP 2, 2006. p.107119.

FERNANDES, A. J. Manual da cana-deaçúcar. Piracicaba: Livroceres, 1990. $196 \mathrm{p}$.

GALLO, D. O. NAKANO, S. S. NETO, R. P. L. et al. Entomologia agrícola. Piracicaba: FEALQ, 2002. 920p.

GARCIA, J. C. Efeitos da adubação orgânica, associada ou não à adubação química, calagem e fosfatagem, nos rendimentos agrícolas e de aguardente teórica da cana-de-açúcar (Saccharum spp). 2005. 82 f. Tese (Doutorado em Fitotecnia) - Universidade Federal de Lavras, Lavras, 2005.

GARCIA, M. P.; SILVA NETO, H. F.; MENDES, S. M. et al. Avaliação da intensidade e grau de Infestação da broca da cana-de-açúcar em relação a diferentes fontes de adubação, safra 2011/2012. 2012. In: XXIV Congresso de Iniciação Científica da UNESP. Resumos... $<$ http://prope.unesp.br/cic/admin/ver_resu mo.php?area $=00073 \&$ subarea $=22158 \&$ con gresso $=34 \& C P F=33669516808$. . 11 agr. 2014.

KOFFLER, N. F.; DONZELLI, P. L. Avaliação dos solos brasileiros para a cultura da cana-de-açúcar. In: Cana-de- 
açúcar: cultivo e utilização. Campinas, Fundação Cargill, v.1, p. 19. 1987.

KORNDÖRFER, G. H.; VIEIRA, G. G.; MARTINS, J. et al. Resposta da cana planta a diferentes fontes de fósforo. Boletim Técnico Copersucar, São Paulo, v.45, n.1, p.31-37, 1989.

LANDELL, M. G. A.; CAMPANA, M. P.; RODRIGUES, A. A. et al. A variedade IAC86-2480 como nova opção de canade-açúcar para fins forrageiros: manejo de produção e uso na alimentação animal. Campinas: IAC, 2002. 36 p. (Boletim Técnico, 193).

MALAVOLTA, E.; VITTI, G. C.; OLIVEIRA, S. Avaliação do estado nutricional das plantas: princípios e aplicações. 2.ed. Piracicaba: Potafós, 1997. 319p.

MARIN, F. R. Clima. Agência de informação Embrapa. Árvore hiperbólica da cana-de-açúcar. 2008. Disponível em: $<$ http://www.agencia.cnptia.embrapa.br/ge stor/cana-de-

acucar/arvore/CONTAG01_10_711200516 716.html>. Acesso: 15 fev. 2015.

MATIOLI, C. S. Irrigação suplementar de cana-de-açúcar (Saccharum ssp) ciclo cana soca: um modelo de análise de decisão para o Estado de São Paulo. 1998. 98p. Tese (Doutorado em Agronomia). Escola Superior de Agricultura "Luiz de Queiroz", Universidade de São Paulo, Piracicaba, 1998.

\section{MOORE, P. H. Sugarcane Biology, Yield} and potential for improvement. Apresentação no Workshop BIOEN sobre melhoramento de cana-de-açúcar, São Paulo, 2009. Disponível em: <http://www.fapesp.br/materia/5064/bioen/ workshop-bioen-onsugarcaneimprovement-18-e-19-3-2009.htm>. Acesso em: 20 fev. 2015.
NUNES JUNIOR, D. Torta de Filtro: de resíduo a produto nobre. Idea News, ano 8, n.92. junho, p.2-30, 2008.

ORLANDO FILHO, J. Calagem e adubação da cana-de-açúcar. In: CÂMARA, G. M. S.; OLIVEIRA, E. A. M. (eds.). Produção de cana-de-açúcar. Piracicaba: FEALQ, 1993. p.133-146.

PENATTI, C. P.; BONI, P. S. Efeito da torta de filtro na cana planta e cana soca. Centro de Tecnologia Copersucar. Relatório Técnico, Piracicaba. 1989. 7p.

QUEVEDO, C. M.; PAGANINI, W. S. Impactos das atividades humanas sobre a dinâmica do fósforo no meio ambiente e seus reflexos na saúde pública. Ciência $\&$ Saúde Coletiva, Rio de Janeiro, v.6, n.8, p. 3529-3539, 2011.

ROSSETTO, R; DIAS, F. L. F. Nutrição e adubação da cana-de-açúcar: indagações e reflexões. In:_, Encarte de Informações Agronômicas, jun. 2005, Piracicaba, n.110, p.10, 2005.

SANTOS, V. R.; MOURA FILHO, G.; ALBUQUERQUE, J. P. V. C. et al. Crescimento e produtividade agrícola de cana-de-açúcar em diferentes fontes de fósforo. Revista Brasileira de Engenharia Agrícola e Ambiental, Campina Grande, v.13, n.4, p. 389-396, 2009. <http://dx.doi.org/10.1590/S141543662009000400004>

UDOP. União dos Produtores de Bioenergia. Valores de ATR e Preço da tonelada de cana-de-açúcar - Consecana do Estado de São Paulo. 2014. <http://www.udop.com.br/cana/tabela_con secana_saopaulo.pdf>. 20 set. 2014.

UNICA. A indústria da cana-de-açúcar, etanol, açúcar e bioeletricidade. 2008. <www.unica.com.br/download.php?idSeca o=17\&id=25497159> .10 ago 2014.

VILELA, P. S. S. Tecnologia para o tratamento de resíduos: tecnologia IFB - 
solubilização biológica de rocha fosfática na produção de fertilizante organofosfatado. Informe Agropecuário, Belo Horizonte, v.26, n.224, p. 47-51, 2005.

VITTI, G. C. Nutrição e adubação da canade-açúcar. Revista Opiniões, abr./jun., p. 37-38, 2010.

VITTI, G. C.; MAZZA, J. A. Planejamento, estratégias de manejo e nutrição da cultura da cana-de-açúcar. Informações Agronômicas, Piracicaba, n.97, 2002, 16p.

VITTI, G. C.; MAZZA, J. A.; QUINTINO, T. A. et al. Nutrição e adubação. In: RIPOLI, T. C. C.; RIPOLI, M. L. C.; CASAGRANDI, D. V. et al. Plantio de cana-de-açúcar: Estado da Arte. Piracicaba: T. C. C. Ripoli, 2006. p. 102144. 